\title{
Highlights
}

- Assessed social problem solving orientation and skill in social anxiety disorder (SAD)

- SAD participants reported more negative and less positive problem orientation than healthy controls

- Participants generated solutions to hypothetical problems from own and others' perspectives

- Coded solutions did not differ in relevance or effectiveness across perspectives or group

- SAD participants generated less active solutions than controls when adopting their own perspective 


\title{
Social Problem Solving in Social Anxiety Disorder
}

\author{
Mia Romano ${ }^{\mathrm{a}^{*}}$, David A. Moscovitch ${ }^{\mathrm{a}}$, Ruofan $\mathrm{Ma}^{\mathrm{a}^{*}}$, \& Jonathan D. Huppert ${ }^{\mathrm{b}}$

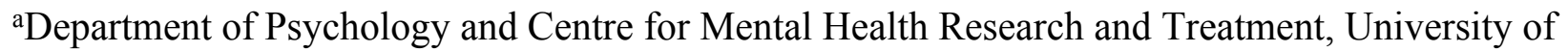 \\ Waterloo \\ ${ }^{b}$ Department of Psychology, The Hebrew University of Jerusalem
}

Correspondence concerning this article should be addressed to David A. Moscovitch, Department of Psychology and Centre for Mental Health Research and Treatment, University of Waterloo; Waterloo, Ontario, Canada N2L-3G1. Phone: 1-519-888-4567 x32549; Fax: 1-519746-8631; Email: dmosco@uwaterloo.ca.

*Mia Romano is currently at Macquarie University, Sydney, Australia

*Ruofan Ma is currently at Michigan State University, East Lansing, MI 


\title{
SOCIAL PROBLEM SOLVING IN SOCIAL ANXIETY
}

\begin{abstract}
Successful social problem solving requires both an adaptive orientation toward the problem and the necessary skills to generate relevant and effective solutions. Surprisingly few studies have examined social problem solving in the context of social anxiety. We examined social problem solving in 38 participants with social anxiety disorder (SAD) in comparison to 30 healthy control (HC) participants with no history of anxiety problems. Participants rated their problem solving attitudes and abilities (i.e., problem orientation) and then generated solutions to hypothetical interpersonal problems from both their own perspective and that of an objective other. These solutions were coded for effectiveness and relevance, as well as the degree to which the solution was active versus passive. Participants with SAD exhibited a more negative problem orientation than HC participants. Furthermore, although SAD and HC participants demonstrated no overall differences in generating relevant and effective solutions to interpersonal problems, utilizing a personal perspective facilitated the generation of more active solutions for $\mathrm{HC}$ participants, but less active solutions for those with SAD. Findings illuminate new research directions regarding social problem solving in social anxiety, with potential implications for applied intervention.
\end{abstract}

Keywords: social anxiety, social problem solving, problem orientation, social skills, self, perspective 
SOCIAL PROBLEM SOLVING IN SOCIAL ANXIETY

\section{Social Problem Solving in Social Anxiety Disorder}

\section{Introduction}

Social problem solving reflects the process through which people generate, select, and implement solutions to problems that arise in everyday life (D’Zurilla \& Nezu, 1999; Dzurilla, Nezu, \& Maydeu-Olivares, 2004; Nezu, 2002). Whether one loses one's wallet, desires a raise from one's boss, or wishes to resolve an argument with one's friend, the demands of daily life are replete with social and interpersonal problems that require effective solutions. Success in this domain depends on a number of factors, including the attitudes and beliefs people hold about their ability to solve problems (their problem orientation) as well as their actual problem solving capacity or skills (D’Zurilla \& Nezu, 1999; D’Zurilla, Nezu, \& Maydeu-Olivares, 2002; Heppner, Witty, \& Dixon, 2004; Nezu, 2004).

How does social anxiety affect social problem solving orientation and skills? Social anxiety heightens the likelihood that one will view social situations as threatening, thus engendering a maladaptive attitude towards social problem solving that is characterized by the tendency to view social problems through a negative lens. Indeed, higher social anxiety in both clinical and non-clinical samples of adults and children has been linked to negative problem orientation (NPO; Fergus, Valentiner, Wu, \& McGrath, 2015; Fergus \& Wu, 2011; Hearn, Donovan, Spence, March, \& Holmes, 2017; Hearn, Donovan, Spence, March, 2017), a cognitive set in which one feels threatened by the problem, doubts one's capacity to solve the problem, and believes that one's efforts will result in negative outcomes (D'Zurilla \& Nezu, 1999). Conversely, a positive problem orientation $(P P O)$ reflects an orientation in which one is optimistic about solving problems, believes in one's own capacity to solve the problem, and perceives the outcome as being worth one's time and effort to attain (D'Zurilla et al., 2002). 


\section{SOCIAL PROBLEM SOLVING IN SOCIAL ANXIETY}

Since social anxiety is commonly characterized by the fear of being socially unskilled (Hofmann, 2000; Moscovitch, 2009), the link to NPO is not surprising, as higher NPO reflects stronger doubt in one's ability to solve social problems. Surprisingly, however, the relationship between PPO and social anxiety has not as yet received research attention, even despite increasing recognition that social anxiety is associated with positivity deficits across numerous domains (Farmer, Kashdan, \& Weeks, 2014). One aim of the present study, therefore, was to use standardized self-report measures to compare negative and positive problem orientation in participants with social anxiety disorder (SAD) versus healthy controls (HC). We hypothesized that SAD participants would report both higher NPO and lower PPO than HC participants.

Moreover, no prior studies have investigated whether socially anxious individuals exhibit actual deficits in their social problem solving skill. It is possible that social anxiety hinders the flexible generation of relevant steps that comprise effective solutions to social problems. Indeed, anxiety-driven avoidance of social situations may deny people valuable opportunities to become well-versed at deriving effective social problem solving strategies. On the other hand, cognitive models of social anxiety suggest that socially anxious individuals may have reasonably intact social skills (an assumption that may extend to generating effective social problem solving strategies), but that cognitive-behavioural factors such as excessive self-focus, ruminative thinking, and use of self-protective avoidance strategies and safety behaviours render them unable to select and implement those skills effectively within anxiety provoking social contexts (e.g., Clark \& Wells, 1995; Hofmann, 2007; Heimberg, Brozovich, \& Rapee, 2010; Rapee \& Heimberg, 1997).

Therefore, it remains an empirical question whether people with higher social anxiety do, in fact, possess normal social problem solving skills, or in other words, an intact capacity to 


\section{SOCIAL PROBLEM SOLVING IN SOCIAL ANXIETY}

generate relevant and effective solutions to social problems. We aimed to answer this question by comparing this capacity in participants with and without SAD. Using the Means-Ends Problem Solving task (MEPS; Platt \& Spivack, 1975), we measured and coded participants’ ability to generate relevant and effective solutions to hypothetical social problems that they imagined confronting both from their own perspective and from the perspective of another person. Given that negative self-perception may inhibit effective social performance in individuals with SAD (Hirsch, Clark, Mathews, \& Williams, 2003; Hirsch, Meynen, \& Clark, 2004; Stopa \& Jenkins, 2007; Rapee \& Abbott, 2007), we expected that priming socially anxious participants to adopt a personal perspective would impede their generation of relevant and effective solutions to interpersonal problems. Moreover, because MEPS responses can be scored as relevant even if they reflect a passive solution (i.e., a solution in which the protagonist takes no active part in solving the problem but relies on the actions of others or the passage of time to solve the problem; Pollock \& Williams, 2004), we also coded the degree to which the protagonist took initiative and was active in solving interpersonal social problems. We hypothesized that participants with SAD, relative to $\mathrm{HC}$ participants, would produce less relevant, effective, and active solutions on the MEPS, but only when directed to solve problems for which they imagined themselves as the central character. Conversely, we expected that participants with SAD would exhibit no deficits in social problem solving when directed to solve problems they imagined others having to face.

\section{Method}

\subsection{Participants}

The study sample consisted of 69 participants, including $31 \mathrm{HC}$ and 38 SAD participants, which according to power analyses was sufficient for the detection of medium effect sizes $(d \geq$ 


\section{SOCIAL PROBLEM SOLVING IN SOCIAL ANXIETY}

$0.5)$ to achieve power of 0.8 . Participants were initially recruited from the community via online and paper advertisements as part of a collaborative anxiety disorders research group at a Canadian university. These advertisements invited individuals with and without anxiety symptoms to contact us by phone or email about joining a research participant pool. Individuals who contacted us were then screened for symptoms of social anxiety and exclusion criteria using an online questionnaire and subsequent phone screen adapted from the Mini International Neuropsychiatric Interview (MINI; Sheehan, 2014), a well-validated semi-structured diagnostic interview (Pinninti, Madison, Musser, \& Rissmiller, 2003; Sheehan et al., 1998). The phone screen comprehensively captured the presence or absence of any essential symptoms that would meet DSM-5 diagnostic criteria (American Psychological Association, 2013). Participants who denied symptoms on the phone screen were eligible to be enrolled in the study as HC participants. Participants who endorsed SAD symptoms were invited to complete an in-person MINI assessment (appended with Anxiety Disorders Interview Schedule symptom checklists (ADIS; Brown \& Barlow, 2014), administered by trained clinical psychology graduate students, and reviewed by two licensed clinical psychologists. Participants who met DSM-5 criteria for a principal diagnosis of SAD (i.e., the SAD diagnosis was deemed the most clinically interfering and/or distressing), with a Clinician Severity Rating of symptoms of 4 or above ( 0 - none to 8 very severe) (i.e., at least moderate levels of distress and impairment caused by SAD) were invited to participate in the current study. Exclusion criteria included endorsement of active and clinically significant suicidality, mania, psychosis, or substance abuse or dependence.

\subsection{Procedure}

All study procedures were approved by the institutional ethics board. Study participants were recruited from among those in our research participant pool with a principal diagnosis of 


\section{SOCIAL PROBLEM SOLVING IN SOCIAL ANXIETY}

SAD. The study was advertised to such individuals as an intervention study about mental images and memories in social anxiety and the recruitment letter informed participants that it would require the completion of a memory interview and social tasks, as well as questionnaires about their social experiences ${ }^{1}$. All participants who met inclusion criteria and provided informed consent to participate in the study attended a pre-treatment laboratory session in which they completed computerized measures on a survey platform hosted by Qualtrics. Participants were first administered self-report measures of social anxiety and depression. Then, participants completed the MEPS task to assess problem solving skill and, finally, completed the Social Problem Solving Inventory-Revised (SPSI-R; D’Zurilla et al., 2002), a self-report measure of problem orientation. Administration always occurred in this order to minimize the potential influence of self-report responses on the SPSI-R priming particular response styles on the MEPS task.

\subsection{Measures}

\subsubsection{Symptom measures}

Social anxiety and depression symptoms were assessed with the Social Phobia Inventory (SPIN; Connor et al., 2000), and the depression subscale of the Depression Anxiety Stress Scales 21-item (DASS-21; Lovibond \& Lovibond, 1995), respectively. Both measures have demonstrated strong psychometric properties in previous studies (Antony, Bieling, Cox, Enns, \& Swinson, 1998; Antony, Coons, McCabe, Ashbaugh, \& Swinson, 2006) and the SPIN can reliably distinguish individuals with versus those without clinical levels of SAD (Antony et al.,

\footnotetext{
${ }^{1}$ The current study reports on data gathered in the context of a larger study concerning the treatment of negative mental images and memories in SAD; details about the intervention conditions and their effects are reported elsewhere (Romano et al., 2019).
} 


\section{SOCIAL PROBLEM SOLVING IN SOCIAL ANXIETY}

2006). Cronbach's alpha in the current study was .96 for the SPIN, and .94 for the depression subscale of the DASS.

\subsubsection{Social Problem Solving Measures}

The Social Problem-Solving Inventory-Revised (SPSI-R; D’Zurilla et al., 2002). To assess problem orientation, we administered the negative orientation (10 items) and positive orientation (5 items) subscales of the SPSI-R. On each subscale, participants rated the extent to which statements such as "I feel threatened and afraid when I have an important problem to solve"”, (NPO) and "When I am faced with a difficult problem, I believe that I will be able to solve it on my own if I try hard enough" (PPO) were true of them on a scale of 0 (Not true of me at all) to 4 (Extremely true of me). Both original and revised versions of the problem orientation subscales have demonstrated sound psychometric properties across a number of samples, including good levels of temporal stability (e.g., coefficient values upwards of .83), and internal consistency (e.g., Cronbach's alpha of .94), as well as convergent and divergent construct validity (e.g., significant relationships with measures assessing internal locus of control and symptoms of psychological distress) (D’Zurilla \& Nezu, 1990; D'Zurilla et al., 2002; Hawkins, Sofronoff, \& Sheffield, 2009). In the present study, Cronbach's alpha was .78 for the PPO subscale and .96 for the NPO subscale.

The Means-End-Problem-Solving Task (MEPS; Platt \& Spivack, 1975). The MEPS measures the ability to conceptualize and generate step-by-step means of (or strategies toward) achieving a goal. The original MEPS consists of 10 vignettes. Each vignette describes the start of a problematic situation followed by a desirable ending, with participants instructed to specify the middle steps that they imagine ought to transpire in order to effectively reach the resolution. Following the methodology of Marx, Williams, \& Claridge (1992) and others (Lyubomirsky \& 


\section{SOCIAL PROBLEM SOLVING IN SOCIAL ANXIETY}

Nolen-Hoeksema, 1995; Watkins \& Baracaia, 2002), we used a shortened version of the MEPS, consisting of MEPS scenarios 2 (argument with your partner), 4 (difficulty with work colleague), 8 (friends avoiding you), and 10 (making new friends), each of which reflects interpersonal problems related to different life areas. These four scenarios were divided into two sets of 2 scenarios that differed according to the problem solving perspective participants were instructed to adopt in their imagination (self vs. other), as described below. Every participant responded to both sets, with the order of administration of the two sets counterbalanced across participants.

MEPS scenarios can be administered by an interviewer or self-administered (Platt \& Spivack, 1975). In the current study, MEPS scenarios were self-administered and participants completed the task individually via computer. For all scenarios, participants were first presented with text on screen describing the situation and were then asked to take 30 seconds to imagine the scenario. Following this, participants were presented with the positive ending and instructed to look for an ideal strategy to the problem presented in the scenario that would lead to the positive ending, and to record their response in a text-box. The experimenter provided instructions and participants completed a practice item to ensure they understood the task. Following this, the experimenter waited outside the lab room while participants completed the task alone.

MEPS Set A: ideal strategy for the self. We reasoned that delivering the MEPS with second-person perspective in the instructions ("Imagine you are...") would impart personal relevance to the situation and therefore shed light on how participants may solve the problem for themselves (Anderson, Goddard, \& Powell, 2009). Thus, in Set A, for MEPS scenarios 8 and 10, we asked participants to imagine the scenario from their own perspective as though they were 
experiencing the scenario themselves, and not as an outside observer. An example of a scenario in Set A is presented below:

You want to have friends and be liked. However, you notice that your friends seem to be avoiding you...

Please record the middle of the story with your ideal strategies here

(The story ends with)...

Your friends start to like you again.

MEPS Set B: ideal strategy for another person. In Set B, we presented MEPS scenarios 2 and 4 from a third-person point of view, instructing participants to imagine the scenarios from an observer's perspective, as though they were watching the character in the scenarios as they unfolded $^{2}$. An example of a scenario in Set B is presented below:

In the following scenario, we will ask you to advise an ideal strategy for Mr. R:

Mr. R. loves his girlfriend very much, but they have many arguments. One day they have an argument and she leaves him...

Please record the middle of the story with your ideal strategies here

(The story ends with)...

Everything becomes fine between Mr. R. and his girlfriend.

MEPS scoring procedure. Two undergraduate coders blind to the diagnostic status of participants were trained in the MEPS coding procedure. They were then randomly assigned to code participant responses. The coders first evaluated each response strategy for relevant means and then for effectiveness and the degree to which they were active. Scoring for relevant means followed the original MEPS scoring procedure. Specifically, a mean was defined as a discrete step (including thoughts) taken to reach the end goal (Heidrich \& Denney, 1994; Platt \&

\footnotetext{
${ }^{2}$ To ensure that participants were adhering to the instructions for each condition (self and other), we inspected language (i.e., pronoun use) utilized in participant MEPS responses across the two sets. Only two participants (one $\mathrm{SAD}$, one $\mathrm{HC}$ ) did not adapt their language use from one type of scenario set to the next, suggesting they may not have distinguished between conditions when asked to imagine from a self or other perspective. Analyses with and without these participants were equivalent, however, so they were retained.
} 


\section{SOCIAL PROBLEM SOLVING IN SOCIAL ANXIETY}

Spivack, 1975). A step was scored as relevant if it enabled the protagonist of the story to progress towards the resolution or overcome any obstacles that prevent him or her from reaching the goal. An example of a mean coded as relevant for the friend scenario (described above) was: "Ask what's up and see if there is anything I can do to help," whereas the response "I would feel very distressed" was not coded as a relevant mean. The total number of relevant steps was summed to obtain a relevance score for the scenario. A relevance score for ideal strategies for the self was then obtained by summing the relevance score for the two scenarios in Set A (scenarios 8 and 10). Similarly, a relevance score for others was obtained by summing the relevance score for the two scenarios in Set B (scenarios 2 and 4$)^{3}$.

When scoring the effectiveness of the MEPS responses, a response was considered effective if it altered the problematic situation and maximized positive and minimized negative consequences (D'Zurilla \& Goldfried, 1971; Nezu, 2004). The effectiveness of the response as a whole was rated on a 3-point Likert-type scale ranging from 0 (not at all effective) to 2 (very effective) (as in Evans, Williams, O’Loughlin, \& Howells, 1992 and Sutherland \& Bryant, 2008). Examples of effectiveness scoring are provided in the Appendix. Effectiveness ratings were then summed separately to obtain overall scores of effectiveness pertaining to scenarios for self and others, respectively.

In addition, each MEPS response was scored to reflect the degree to which it was active or passive on a scale of 0 to 5 , with higher scores reflecting more active solutions. Higher scores

\footnotetext{
${ }^{3}$ To ensure that relevance scores were not an artifact of MEPS response length, we analyzed the word count for responses to Set A, Set B, and overall. Analyses demonstrated that there were no significant differences between condition (self vs. other) on the length of participant responses: Self: $M=130.22(S D=83.39)$; Other: $M=119.85$ $(S D=60.37), t_{(67)}=1.60, p=.115$; nor were there differences between groups (SAD vs. HC) on the length of MEPS responses generated for Self: SAD: $M=129.00(S D=77.81)$; $\mathrm{HC}: M=131.77(S D=91.30), t_{(66)}=.14, p=.893$; Other: SAD: $M=119.42(S D=54.69)$; HC: $M=120.40(S D=67.84), t_{(66)}=.07, p=.948$ and; Overall; SAD: $M=$ $248.42(S D=122.29)$; HC: $M=252.17(S D=152.49), t_{(66)}=.11, p=.911$.
} 


\section{SOCIAL PROBLEM SOLVING IN SOCIAL ANXIETY}

were obtained if the protagonist took the initiative and was active in solving the problem; for example: "I directly ask my friends why they are avoiding me." Lower scores were obtained if the protagonist took no active part in solving the problem but relied on the actions of others, the passage of time, or fate, luck or chance for the problem to resolve itself (as in Pollock \& Williams, 2004, Quiñones, Jurska, Fener, \& Miranda, 2015, and Sutherland \& Bryant, 2008). For example: "I don't do anything and instead wait until I happen to see them again." Ratings were then summed separately for scenarios pertaining to self and other to obtain overall scores for the degree to which the response was active ${ }^{4}$.

A randomly selected sample of MEPS responses (20\%) from the total pool of coded responses $(n=69)$ were double coded by each coder. Reliability between coders was then estimated with the intraclass correlation coefficient (ICC; Shrout \& Fleiss, 1979). Cicchetti's (1994) criterion identifies ICC's below .40 as showing poor agreement, .40 to .59 as fair agreement, .60 to .74 as good agreement, and .75 as excellent agreement. ICCs (two-way mixed, absolute agreement) were $.76, .74$, and .79 for self, other, and total number of relevant means, respectively, and $.65, .93$, and .91 for self, other, and total effectiveness, respectively. Raters showed strong agreement on the degree to which MEPS solutions were active, with ICC values of .91 for ratings pertaining to self, other, and overall.

\subsection{Data screening and preparation}

\footnotetext{
${ }^{4}$ If a problem solution was rated as having no means (i.e., a relevance score of 0 ), the effectiveness of the solution and the degree to which it was active were not rated. An example of a MEPS response that was rated as having no means, and achieved a relevance score of 0 is as follows: "This is not a scenario that I have any sort of skill in. Getting from point A to point B on this journey is foreign to me. So I call upon a magical wizard to cast a spell on me that miraculously gives me the confidence to go out and meet new people." Four responses in Set A (self) and seven responses in Set B (others) were rated as having no means. Of the responses scored 0 in Set A, two were from the SAD group and five from the $\mathrm{HC}$ group. Of the responses scored 0 in Set $\mathrm{B}$, three were from the SAD group and one from the $\mathrm{HC}$ group.
} 


\section{SOCIAL PROBLEM SOLVING IN SOCIAL ANXIETY}

Data integrity checks included valid values and range checks. Outliers were screened within groups according to the modified z-score method which relies on the median absolute value (here we used a value of 3.5) to detect serious anomalies. Any detected values that were impossible or highly improbable for a given measure were then removed from relevant analyses (described below). The assumption of normality for all variables was explored by examining absolute values of skewness and kurtosis and with the Shapiro-Wilk (S-W) test of normality, and visual examination of Q-Q plots. The following variables were associated with slight distribution problems (i.e., restricted range/non-normal): SPIN scores in the control group, DASS-Depression scores in both groups, and MEPS effectiveness and active scores (self and other) in both groups. Considering problems with transforming and then interpreting transformed variables (GarcíaPérez, 2012), the distributions were left untransformed. To ensure the integrity of obtained findings, all $t$-tests were replicated using a 95\% bias-corrected confidence-interval bootstrapping procedure in SPSS (Efron \& Tibshirani, 1985; Preacher \& Hayes, 2004), which is robust to nonnormally distributed data (Shrout \& Bolger, 2002) ${ }^{5}$. Homogeneity of variance was violated in analyses pertaining to the SPIN, DASS-Depression, NPO, and the degree to which self-solutions were active; therefore, the t-test statistic that does not assume equal variances is reported for these analyses.

\subsection{Missing and excluded data}

Two control participants were excluded from analyses pertaining to SPSI-R PPO and NPO: one due to a Qualtrics recording failure and one due to indiscriminate responding. One additional control participant achieved an outlying score on the MEPS active (self) variable (a modified z-score of 5.4), and was removed from analyses pertaining to that variable. Finally, one

${ }^{5}$ We also ensured the accuracy of results from the repeated measures ANOVA's by replicating follow-up t-tests with bootstrapping. The pattern of results remained unchanged when the bootstrapping procedure was performed. 


\section{SOCIAL PROBLEM SOLVING IN SOCIAL ANXIETY}

control participant was excluded from all analyses due to endorsing past treatment for psychological difficulties and exhibiting unusually high SPIN scores on the day of testing as well as outlying score on the NPO scale.

\section{Results}

\subsection{Equivalence of groups}

There were no significant differences between SAD and HC participants in demographic characteristics, but as expected, the two groups differed on symptom measures of social anxiety and depression, with SAD participants self-reporting higher symptom levels than HC participants (see Table 1).

\subsection{Social problem solving}

Table 2 presents the descriptive statistics for social problem solving orientation and skill variables. Correlations between each of the study variables are presented in Table 3. Cohen's $d$ effect sizes were calculated for all significant group comparisons, with established conventions for small, medium, and large effects corresponding with values of $0.2,0.5$, and 0.8 , respectively (Cohen, 1988).

Problem Orientation: Relative to HC participants, participants with SAD demonstrated significantly higher levels of NPO $\left(t_{(62.64)}=-13.25, p<.001, d=3.09[2.34,3.76]\right)$, and lower levels of PPO $\left(t_{(64)}=4.54, p<.001, d=-1.13[-1.64,-0.59]\right)$. Within their respective groups, participants with SAD demonstrated significantly higher NPO compared to PPO $\left(t_{(37)}=9.42, p\right.$ $<.001, d=1.53,95 \%$ CI $[1.05,1.99])$, while HC participants demonstrated significantly lower NPO relative to PPO $\left(t_{(27)}=-6.98, p<.001, d=1.31,95 \%\right.$ CI $\left.[0.56,1.68]\right)$.

Social Problem Solving Skills: In order to assess the impact of diagnostic status (SAD vs. HC) and perspective (self vs. other) on MEPS performance, three repeated measures 


\section{SOCIAL PROBLEM SOLVING IN SOCIAL ANXIETY}

ANOVAs were conducted with group and perspective entered as the predictor variables, and scores for MEPS relevance, effectiveness, and the degree to which the solution was active as dependent variables in separate analyses. With respect to the relevance of MEPS solutions, main effects were non-significant for both perspective, $F_{(1,66)}=1.62, p=.208, \square_{\mathrm{p}}^{2}=.02$, and group, $F_{(1,66)}=0.27, p=.608, \square_{\mathrm{p}}^{2}=.00$. The interaction between perspective and group approached significance, $F_{(1,66)}=3.71, p=.058, \square_{\mathrm{p}}^{2}=.05$ (see Table 2 for descriptive statistics). With respect to the effectiveness of MEPS solutions, the main effect of perspective approached significance, $F_{(1,57)}=3.63, p=.062, \square_{\mathrm{p}}^{2}=.06$. The main effect of group was non-significant, $F_{(1,57)}=1.57, p=.215, \square_{\mathrm{p}}^{2}=.03$. The interaction between perspective and group was also nonsignificant, $F_{(1,57)}=2.68, p=.107, \square_{\mathrm{p}}^{2}=.05$. With respect to the degree to which solutions were active, there was non-significant main effect of perspective, $F_{(1,56)}=1.68, p=.200, \square_{\mathrm{p}}^{2}=.03$, and group, $F_{(1,56)}=0.76, p=.761, \square_{\mathrm{p}}^{2}=.00$; however, these results were qualified with a significant interaction between perspective and group, $F_{(1,56)}=8.80, p=.004, \square_{\mathrm{p}}^{2}=.14$. The estimated marginal means demonstrated that participants in the SAD group developed less active solutions for themselves compared to others (Self: $M: 7.71(S E=0.36)$ Other: $M: 8.29$ (SE $=$ 0.34), while participants in the HC group developed more active solutions for themselves compared to others (Self: $M: 8.88(S E=0.42)$ Other: M: $7.38(\mathrm{SE}=0.40)$. Follow-up betweengroup contrasts demonstrated that participants with SAD relative to $\mathrm{HC}$ participants generated less active solutions for themselves, $\left(t_{(55.86)}=2.27, p=.038, d=-0.56[-1.09,-0.02]\right)$, though the two groups did not differ in active solutions for others, $\left(t_{(56)}=-1.75, p=.087, d=0.46[-0.07\right.$, 0.98]). Within-group contrasts demonstrated that HC participants generated more active solutions for themselves than for others $\left(t_{(23)}=-3.94, p=.001, d=-0.83,95 \%\right.$ CI [-1.59, -0.39$\left.]\right)$, whereas participants with SAD did not differ in the extent to which their solutions were active 
when generated for themselves vs. for others $\left(t_{(33)} 1.12, p=.271 ; d=0.19,95 \%\right.$ CI [-0.31, $0.65])^{6}$. This interaction effect is depicted graphically in Figure 1.

\section{Discussion}

In the present study, we compared participants with and without a diagnosis of SAD on measures of social problem solving orientation and skill. Participants with SAD demonstrated significantly higher scores on NPO compared to both PPO and the control group, supporting our hypothesis about problem solving orientation. Moreover, HC participants demonstrated higher PPO compared to both NPO and the clinical group. These results support prior research indicating that individuals with SAD possess negative attitudes towards solving social problems (Fergus et al., 2015; Fergus \& Wu, 2011; Hearn, Donovan, Spence, \& March, 2017; Hearn, Donovan, Spence, March, \& Holmes, 2017), but also suggest that positive attitudes may be dampened, a finding that is unique to the current study. Possessing more negative and less positive attitudes may hinder the problem solving process of socially anxious individuals in the real world. These attitudes may converge with negative self-schema reflecting their inability to make desired impressions on others (Hofmann, 2000; McEvoy \& Mahoney, 2012; Schlenker \& Leary, 1982). The significant correlations between problem orientation and symptoms of both social anxiety and depression also align with the view that NPO may serve as a transdiagnostic marker of general psychopathology (e.g., Fergus et al., 2015; Fergus \& Wu, 2011).

\footnotetext{
${ }^{6}$ Because prior research has indicated that a diagnosis of depression may account for performance on MEPS variables, we conducted sensitivity analyses to determine if our results could be accounted for by the presence of a comorbid mood disorder. In these analyses we removed any participant in the SAD group who also had a diagnosed mood disorder (9 participants) and found that results pertaining to the effectiveness of solutions and the degree to which they were active remained consistent with the original results reported. However, the results for the relevance of solutions differed such that the interaction between perspective and group became significant $\left(F_{(1,57)}=5.58, p=\right.$ $\left..022, \square_{\mathrm{p}}^{2}=.09\right)$. Follow-up between-group contrasts demonstrated that both groups of participants generated a similar number of relevant steps for the self $\left(t_{(57)}=1.40, p=.166\right)$, and others $\left(t_{(57)}=-0.56, p=.577\right)$. Within-group contrasts demonstrated that HC participants generated more relevant solutions for themselves than for others $\left(t_{(29)}=\right.$ $-2.29, p=.030)$, whereas participants with SAD generated similarly relevant solutions for themselves and others $\left(t_{(28)} 1.08, p=.288\right)$.
} 


\section{SOCIAL PROBLEM SOLVING IN SOCIAL ANXIETY}

With respect to our hypothesis about participants' capacity to generate skillful solutions to imagined problems, participants with and without SAD did not differ in the relevance and effectiveness of the solutions they generated overall in response to hypothetical MEPS scenarios, suggesting that individuals with SAD may not exhibit problem solving skill deficits in general, at least when solving hypothetical problems. This finding aligns with past research which has failed to find deficits on MEPS solutions for hypothetical scenarios in participants with elevations in symptoms of anxiety (Anderson et al., 2009) or a clinical diagnosis of agoraphobia (Brodbeck \& Michelson, 1987). A prior study (Marx et al., 1992) found that clinically anxious individuals demonstrated some deficits in hypothetical problem solving in comparison to non-clinical control participants; however, even despite such deficits they were able to develop effective ideal solutions for both hypothetical and personal problems, whereas clinically depressed individuals were not. Marx and colleagues concluded that people with depression versus those with anxiety disorders may struggle with different stages of the problem solving process, with depressed individuals having difficulty generating problem solutions, which is captured on the MEPS, and anxious individuals struggling to implement those solutions, which would not be captured on the MEPS. Difficulty with implementation may be particularly relevant for those with SAD; indeed, even if they are capable of solving interpersonal problems in their imagination, a self-protective and avoidant attitude toward social situations may prevent socially anxious individuals from implementing those solutions effectively. In this way, our findings may be consistent with CBT models of $\mathrm{SAD}$, which suggest that socially anxious individuals often possess adequate social skills, but that cognitive-behavioural factors such as excessive self-focus and safety behaviours render them unable to implement those skills effectively within anxiety provoking social contexts (e.g., Clark \& Wells, 1995; Rapee \& Heimberg, 1997). 


\section{SOCIAL PROBLEM SOLVING IN SOCIAL ANXIETY}

Notably, results demonstrated a significant interaction between perspective (self vs. other) and diagnostic status when predicting the degree to which solutions were rated as active. Between-group follow-up analyses showed that HC participants generated more active solutions for the self than SAD participants, though the groups did not differ in the extent to which they generated active solutions for others. This discrepancy supports the notion that individuals with SAD appear to possess the requisite knowledge to take active initiative to generate solutions to interpersonal problems when they imagine others as the central character but when they have to solve a problem from their own point of view, they may be more likely to adopt a passive style characterized by inhibition and the reliance on others to initiate problem resolution. This finding aligns with the results of Brodbeck and Michelson (1987), who found that while participants with agoraphobia could generate effective responses to interpersonal problems, they tended to select avoidant responses as being behaviourally preferred. For those with SAD, a personalized perspective may induce fears of negative evaluation that may thwart the development of solutions to interpersonal problems that involve taking initiative and responding assertively, and may instead facilitate the development of what may be considered a behaviourally preferred response, such as those solutions characterized by passivity and avoidance.

Although the interaction between perspective (self vs. other) and group (SAD vs. HC) did not reach the threshold for statistical significance, an examination of the means in Table 2 appeared to indicate that when asked to imagine themselves as the central character, $\mathrm{HC}$ participants exhibited an increase in the relevance of their solutions relative to when they imagined another person as the central character (whereas this pattern did not occur for participants with SAD). For socially anxious participants, negative self-referent biases, including negative imagery, may have impeded the generation of optimal solutions when interpersonal 


\section{SOCIAL PROBLEM SOLVING IN SOCIAL ANXIETY}

scenarios were viewed from the perspective of the self. An examination of MEPS responses indicated that participants with SAD often commented on their social shortcomings in response to the hypothetical scenarios, particularly when viewed from one's own perspective. For instance, in response to the "making friends" scenario, one such participant said: "It's snowy outside. I grab my shovel and run out to shovel our sidewalks. I do the neighbour's sidewalks as well. The neighbour comes outside to start his car. He says hello and I say that I love the snow and we didn't get as much as I liked where we moved from. Then I think that was a dumb thing to say and he probably thinks I am an idiot. I keep shoveling because it would look really weird to stop in the middle of the job." In this example, while the participant began with helpful strategies for initiating a friendship, the negative thoughts that intrude on the scenario appear to hinder the development of a well-rounded solution that would clearly lead to a positive outcome in this situation. However, the pattern of means should be interpreted with caution, as our formal analyses did not detect statistical differences in the relevance and effectiveness of solutions for SAD participants, perhaps due to limited power.

There are several limitations of the present study, which also highlight avenues for future research. First, our data cannot shed light on how social anxiety symptoms and problem solving processes interact in the real world. Partly, this concerns the ecological validity of the MEPS task. It is possible that participants' responses did not resemble the types of solutions they would offer if confronted with real-life personalized problems. For example, the MEPS tasks specified a particular ending for each scenario presented. Even if people with SAD could imagine and describe an ideal strategy for solving a social problem, social situations in real life are full of surprises. It would be essential to assess whether socially anxious individuals could effectively handle these unexpected challenges and actually resolve a social problem with success. 


\section{SOCIAL PROBLEM SOLVING IN SOCIAL ANXIETY}

Furthermore, although social problems often contain ambiguous resolutions, the endings provided in the MEPS scenarios were standardized to be decidedly positive, thus prohibiting us from discerning whether socially anxious individuals may struggle to identify problem solutions in contexts with more ambiguous social outcomes. Indeed, ambiguous endings may be more likely to generate appraisals of outcomes as negative, perhaps due to heightened intolerance of uncertainty in people with SAD (e.g., Antony \& Rowa, 2008; Boelen \& Reijntjes, 2009; Carleton, Collimore, \& Asmundson, 2010).

Moreover, although individuals with SAD showed significantly more negative and less positive attitudes towards social problem solving, we cannot dissect whether such attitudes and social anxiety symptoms are causally related or which emerged first. It is possible, as suggested by D'Zurilla and Goldfried (1971), that maladaptive problem orientation could lead to more daily challenges and thus result in the cognitive biases characteristic of SAD. On the other hand, it may be that the maladaptive cognitive processes associated with SAD prevent adaptive confrontation of problem situations, maintaining negative perspectives towards social problems for people with high social anxiety. Future studies could employ longitudinal designs to examine the order in which problem orientation and social anxiety symptoms appear. Given that NPO has been shown to decrease as a result of CBT (Hearn, Donovan, Spence, \& March, 2018), experimental research that manipulates problem orientation might also shed light on its effects in social anxiety. Whether or not problem orientation impacts actual problem solving ability in the real-world may also be important to consider. In the current sample, NPO and PPO were not significantly correlated with the quality of MEPS solutions; however, NPO was significantly associated with the degree to which problem solutions for the self were rated as active. This 


\section{SOCIAL PROBLEM SOLVING IN SOCIAL ANXIETY}

might support the notion that NPO may hinder self-initiated steps to solve interpersonal problems.

While we attempted to induce self and other focus during the MEPS task (e.g., Anderson et al., 2009; Hasegawa et al., 2016; Marx et al., 1992), we did not assess the degree to which participants followed instructions to imagine the scenarios in second or third person. An examination of pronoun use indicated that participants were discriminating between responses for self and other but we cannot be certain that participants imagined these scenarios from the perspective represented in the task instructions. Given that individuals with SAD might naturally adopt an observer perspective (Wells, Clark, \& Ahmad, 1998; Wells \& Papageorgiou, 1999), it is possible that participants with SAD had difficulty shifting perspectives for the hypothetical scenarios. In addition, because social scenarios induce greater self-focus in SAD (e.g., Clark \& Wells, 1995; Rapee \& Heimberg, 1997), third-person characters may have been imagined to possess similar characteristics as the participants themselves. In either case, the way in which the scenarios or characters were imagined may have impacted MEPS solutions. Also, although prior research tends to distinguish between MEPS relevance and effectiveness as different outcomes, the two variables were highly correlated in the current study $(r=.69$ and .75 for self and others, respectively). It is unclear whether these two scores should be considered redundant, as they are both operationalized in specific ways that differ from each other both conceptually and procedurally; however, it would be important for future research to determine the uniqueness of each construct, particularly because prior studies have also shown similarly high correlations (e.g., $r=.63, r=0.76$, and $r=0.72$, in Anderson et al., 2009, Kaviani, Rahimi, Rahimi-Darabad, Kamyar, \& Naghavi, 2003, and Ruby, Smallwood, Sackur, \& Singer, 2013, respectively). 


\section{SOCIAL PROBLEM SOLVING IN SOCIAL ANXIETY}

Although we recruited community participants, our overall sample was relatively young $(<30$ years of age) and well-educated. As such, our findings may not generalize to groups of individuals who demonstrate more variable demographic characteristics. Moreover, we cannot draw any firm conclusions about the potential effects of comorbid conditions on group differences. Given prior research suggesting that a clinical diagnosis of depression may be associated with MEPS skill deficits, we conducted sensitivity analyses to determine if our findings could be accounted for by a clinical diagnosis of depression. The results of these analyses were generally consistent and, in fact, when we removed participants with comorbid clinical depression, a significant interaction for the relevance of solutions emerged between group and perspective, perhaps suggesting that a SAD diagnosis in particular drove this interaction effect. Given the post-hoc and exploratory nature of these findings, we hesitate to draw any firm conclusions from them. It would be worthwhile for future research to include a group of depressed individuals with no history of social anxiety to test a priori hypotheses about the potential roles of SAD vs. depression on social problem solving more directly. Finally, it would be important to replicate these results with larger samples in order to ensure sufficient power to detect small effects between groups.

Despite these limitations, the current study is the first that we know of to examine both social problem solving orientation and skill in a sample of adults diagnosed with SAD. Results suggest that interventions for SAD could benefit patients by targeting various stages of the problem solving process, including maladaptive attitudes towards social problems and poorer ability to generate active solutions to interpersonal problems, at least when imaging oneself as the problem solver. 
SOCIAL PROBLEM SOLVING IN SOCIAL ANXIETY 


\section{SOCIAL PROBLEM SOLVING IN SOCIAL ANXIETY}

\section{Acknowledgements}

We wish to thank research collaborators Drs. Morris Moscovitch and Susanna Reimer for

their guidance and support, as well as research assistants Kerri Adams, Zoya Amir, and Prabhjot Saini, whose hard work was integral to the completion of this study.

Funding: This work was supported by research operating grants from the Canadian Institutes of Health Research and the Social Sciences and Humanities Research Council of Canada.

Declarations of interest: none. 
SOCIAL PROBLEM SOLVING IN SOCIAL ANXIETY

\section{References}

American Psychiatric Association. (2013). Diagnostic and statistical manual of mental disorders (5 $5^{\text {th }}$ ed.). Washington, DC: American Psychiatric Association.

Anderson, R. J., Goddard, L., \& Powell, J. H. (2009). Social problem-solving processes and mood in college students: An examination of self-report and performance-based approaches. Cognitive Therapy and Research, 33, 175-186.

Antony, M. M., Bieling, P. J., Cox, B. J., Enns, M. W., \& Swinson, R. P. (1998). Psychometric properties of the 42-item and 21-item versions of the Depression Anxiety Stress Scales in clinical groups and a community sample. Psychological Assessment, 10, 176-181.

Antony, M. M., Coons, M. J., McCabe, R. E., Ashbaugh, A., \& Swinson, R. P. (2006).

Psychometric properties of the social phobia inventory: Further evaluation. Behaviour Research and Therapy, 44, 1177-1185.

Antony, M. M, \& Rowa, K. (2008). Social anxiety disorder. Ashland, OH: Hogrefe \& Huber Publishers.

Boelen, P. A., \& Reijntjes, A. (2009). Intolerance of uncertainty and social anxiety. Journal of Anxiety Disorders, 23, 130-135.

Brodbeck, C., \& Michelson, L. (1987). Problem-solving skills and attributional styles of agoraphobics. Cognitive Therapy and Research, 11, 593-610.

Brown, T. A., \& Barlow, D. H. (2014). Anxiety and Related Disorders Interview Schedule for DSM-5 (ADIS-5): Adult Version. Client Interview Schedule. Oxford University Press.

Carleton, R. N., Collimore, K. C., \& Asmundson, G. J. (2010). "It's not just the judgements—It's that I don't know": Intolerance of uncertainty as a predictor of social anxiety. Journal of Anxiety Disorders, 24, 189-195 


\section{SOCIAL PROBLEM SOLVING IN SOCIAL ANXIETY}

Cicchetti, D. V. (1994). Guidelines, criteria, and rules of thumb for evaluating normed and standardized assessment instruments in psychology. Psychological Assessment, 6, 284290.

Clark, D. M., \& Wells, A. (1995). A cognitive model of social phobia. In R. G. Heimberg, M. R. Liebowitz, D. A. Hope, \& F. R. Schneier (Eds.), Social phobia: Diagnosis, assessment and treatment (pp. 69-93). New York, NY: Guilford.

Cohen, J. (1988). Statistical Power Analysis for the Behavioral Sciences. London, UK:

Routledge

Connor, K. M., Davidson, J. R., Churchill, L. E., Sherwood, A., Weisler, R. H., \& Foa, E. (2000). Psychometric properties of the Social Phobia Inventory (SPIN): New self-rating scale. The British Journal of Psychiatry, 176, 379-386.

D'Zurilla, T. J., \& Goldfried, M. R. (1971). Problem solving and behavior modification. Journal of Abnormal Psychology, 78,107-126.

D'Zurilla, T. J., \& Nezu, A. M. (1990). Development and preliminary evaluation of the Social Problem-Solving Inventory (SPSI). Psychological Assessment: A Journal of Consulting and Clinical Psychology, 2, 156-163.

D’Zurilla, T. J., \& Nezu, A. M. (1999). Problem-solving therapy: A social competence approach to clinical intervention (2nd ed.). New York: Springer.

D’Zurilla, T. J., Nezu, A. M., \& Maydeu-Olivares, A. (2002). Manual for the Social ProblemSolving Inventory-Revised. North Tonawanda, NY:Multi-Health Systems

D'Zurilla, T. J., Nezu, A. M., \& Maydeu-Olivares, A. (2004). Social Problem Solving: Theory and Assessment. In E. C. Chang, T. J. D'Zurilla, \& L. J. Sanna (Eds.), Social problem 


\section{SOCIAL PROBLEM SOLVING IN SOCIAL ANXIETY}

solving: Theory, research, and training (pp. 11-27). Washington, DC, US: American Psychological Association.

Efron, B., \& Tibshirani,R. (1985). The bootstrap method for assessing statistical accuracy. Behaviormetrika, 17, 1-35.

Evans, J., Williams, J. M., O'Loughlin, S., \& Howells, K. (1992). Autobiographical memory and problem-solving strategies of parasuicide patients. Psychological Medicine, 22, 399-405.

Farmer, A. S., Kashdan, T. B., \& Weeks, J.W. (2014). Positivity deficits in social anxiety: Emotions, events, and cognitions. In S. G Hofmann \& P. M Dibartolo (Eds.), Social anxiety: Clinical, developmental, and social perspectives (pp. 551-578). San Diego: Elsevier.

Fergus, T. A., Valentiner, D. P., Wu, K. D., \& McGrath, P. B. (2015). Examining the symptomlevel specificity of negative problem orientation in a clinical sample. Cognitive Behaviour Therapy, 44, 153-161.

Fergus, T. A., \& Wu, K. D. (2011). Searching for specificity between cognitive vulnerabilities and mood and anxiety symptoms. Journal of Psychopathology and Behavioral Assessment, 33, 446.

García-Pérez, M. A. (2012). Statistical conclusion validity: Some common threats and simple remedies. Frontiers in Psychology, 3, 1-11.

Hawkins, D., Sofronoff, K., \&Sheffield, J. (2009). Psychometric properties of the Social Problem Solving Inventory-Revised Short-Form: Is the short form a valid and reliable measure for young adults? Cognitive Therapy Research, 33, 462-470.

Hasegawa, A., Nishimura, H., Mastuda, Y., Kunisato, Y., Morimoto, H., \& Adachi, M. (2016). Is Trait Rumination Associated with the Ability to Generate Effective Problem Solving 


\section{SOCIAL PROBLEM SOLVING IN SOCIAL ANXIETY}

Strategies? Utilizing Two Versions of the Means-Ends Problem-Solving Test. Journal of Rational - Emotive and Cognitive - Behavior Therapy, 34, 14-30.

Hearn, C. S., Donovan, C. L., Spence, S. H., \& March, S. (2017). A worrying trend in Social Anxiety: To what degree are worry and its cognitive factors associated with youth Social Anxiety Disorder? Journal of Affective Disorders, 208, 33-40.

Hearn, C. S., Donovan, C. L., Spence, S. H., \& March, S. (2018). Do worry and its associated cognitive variables alter following CBT treatment in a youth population with Social Anxiety Disorder? Results from a randomized controlled trial. Journal of Anxiety Disorders, 53, 4657.

Hearn, C. S., Donovan, C. L., Spence, S. H., March, S., \& Holmes, M. C. (2017). What's the worry with social anxiety? Comparing cognitive processes in children with Generalized Anxiety Disorder and Social Anxiety Disorder. Child Psychiatry \& Human Development, 48, 786-795.

Heidrich, S. M., \& Denney, N. W. (1994). Does social problem solving differ from other types of problem solving during the adult years? Experimental Aging Research, 20, 105-126.

Heimberg, R. G., Brozovich, F. A., \& Rapee, R. M. (2010). A cognitive behavioral model of social anxiety disorder: Update and extension. In Social Anxiety (Second Edition) (pp. 395422). Amsterdam; Boston: Elsevier

Heppner, P. P., Witty, T. E., \& Dixon, W. A. (2004). Problem-solving appraisal and human adjustment: A review of 20 years of research using the Problem Solving Inventory. The Counseling Psychologist, 32, 344-428.

Hirsch, C. R., Clark, D. M., Mathews, A., \& Williams, R. (2003) Self-images play a causal role in social phobia. Behaviour Research and Therapy, 41, 909-921. 


\section{SOCIAL PROBLEM SOLVING IN SOCIAL ANXIETY}

Hirsch, C. R., Meynen, T., \& Clark, D. M. (2004) Negative self-imagery in social anxiety contaminates social interactions. Memory, 12, 496-506.

Hofmann, S. G. (2000). Self-focused attention before and after treatment of social phobia. Behaviour Research and Therapy, 38, 717-725.

Hofmann, S. G. (2007). Cognitive factors that maintain social anxiety disorder: A comprehensive model and its treatment implications. Cognitive Behaviour Therapy, 36, 193-209.

Kaviani, H., Rahimi, M., Rahimi-Darabad, P., \& Naghavi, K. K. H. (2003). How autobiographical memory deficits affect problem-solving in depressed patients. Acta Medica Iranica, 194-198.

Lovibond, P. F., \& Lovibond, S. H. (1995). The structure of negative emotional states: Comparison of the Depression Anxiety Stress Scales (DASS) with the Beck Depression and Anxiety Inventories. Behaviour Research and Therapy, 33, 335-342.

Lyubomirsky, S., \& Nolen-Howksema, S. (1995). Effects of self-focused rumination on negative thinking and interpersonal problem-solving. Journal of Personality and Social Psychology, $69,176-190$.

Marx, E. M., Williams, J. M., \& Claridge, G. C. (1992). Depression and social problem solving. Journal of Abnormal Psychology, 101, 78-86.

McEvoy, P. M., \& Mahoney, A. (2012). To be sure, to be sure: Intolerance of uncertainty mediates symptoms of various anxiety disorders and depression. Behavior Therapy, 43, $533-545$.

Moscovitch, D. A. (2009). What is the core fear in social phobia? A new model to facilitate individualized case conceptualization and treatment. Cognitive and Behavioral Practice, 16, 123-134. 


\section{SOCIAL PROBLEM SOLVING IN SOCIAL ANXIETY}

Nezu, A. M. (2002). Problem-solving therapy. In T. Scrimali \& L. Grimaldi (Eds.), Cognitive psychotherapy toward a new millennium: Scientific foundations and clinical practice (pp. 89-94). New York: Kluwer Academic Publishers.

Nezu, A. M. (2004). Problem solving and behavior therapy revisited. Behavior Therapy, 35, 133.

Pinninti, N. R., Madison, H., Musser, E., \& Rissmiller, D. (2003). MINI International Neuropsychiatric Schedule: Clinical utility and patient acceptance. European Psychiatry, $18,361-364$

Platt, J. J., \& Spivack, G. (1975). Manual for the Means-Ends Problem-Solving Procedure (MEPS): A measure of interpersonal cognitive problem-solving skills. Philadelphia: Hahnemann Community Mental Health/Mental Retardation Center.

Pollock, L. R., \& Williams, J. M. G. (2004). Problem-solving in suicide attempters. Psychological Medicine, 34, 163-167.

Preacher, K. J., \& Hayes, A. F. (2004). SPSS and SAS procedures for estimating indirect effects in simple mediation models. Behavior Research Methods, Instruments, \& Computers, 36, $717-731$

Quiñones, V., Jurska, J., Fener, E., \& Miranda, R. (2015). Active and passive problem solving: Moderating role in the relation between depressive symptoms and future suicidal ideation varies by suicide attempt history. Journal of Clinical Psychology, 71, 402-412.

Rapee, R. N., \& Heimberg, R. G. (1997). A cognitive-behavioral model of anxiety in social phobia. Behaviour Research and Therapy, 35, 741-756.

Rapee, R. M., \& Abbott, M. J. (2007). Modelling relationships between cognitive variables during and following public speaking in participants with social phobia. Behaviour 


\section{SOCIAL PROBLEM SOLVING IN SOCIAL ANXIETY}

Research and Therapy, 45, 2977-2989.

Romano, M., Moscovitch, D.A., Huppert, J.D., Reimer, S.G., \& Moscovitch, M. (under review). Imagery rescripting for social anxiety disorder: Dismantling the unique effects of rescripting on memory representations and core belief updating. Journal of Anxiety Disorders.

Ruby, F. J., Smallwood, J., Sackur, J., \& Singer, T. (2013). Is self-generated thought a means of social problem solving?. Frontiers in psychology, 4, 1-10.

Schlenker, B. R., \& Leary, M. R. (1982). Social anxiety and self-presentation: A conceptualization model. Psychological Bulletin, 9, 641.

Sheehan, D. V. (2014). The Mini-International Neuropsychiatric Interview, Version 7.0 for DSM-5 (M.I.N.I 7.0). Jacksonville FL: Medical Outcomes Systems

Sheehan, D. V., Lecrubier, Y., Sheehan, K. H., Amorim, P., Janavs, J., Weiller, E., . . . Dunbar, G. C. (1998). The Mini-International Neuropsychiatric Interview (M.I.N.I): The development and validation of a structured diagnostic psychiatric interview for DSM-IV and ICD-10. The Journal of Clinical Psychiatry, 59(Suppl 20), 22-33.

Shrout, P. E., \& Bolger, N. (2002). Mediation in experimental and nonexperimental studies: New procedures and recommendations. Psychological Methods, 7, 422-445.

Shrout, P. E., \& Fleiss, J. L. (1979). Intraclass correlations: Uses in assessing rater reliability. Psychological Bulletin, 86, 420-428.

Sutherland, K., \& Bryant, R. A. (2008). Social problem solving and autobiographical memory in posttraumatic stress disorder. Behaviour Research and Therapy, 46, 154-161. 


\section{SOCIAL PROBLEM SOLVING IN SOCIAL ANXIETY}

Stopa, L., \& Jenkins, A. (2007). Images of the self in social anxiety: Effects on the retrieval of autobiographical memories. Journal of Behavior Therapy and Experimental Psychiatry, 38, 459-473.

Watkins E., \& Baracaia S. (2002). Rumination and social problem solving in depression. Behaviour Research and Therapy, 40, 1179-89.

Wells, A., Clark, D. M., \& Ahmad, S. (1998). How do I look with my minds eye: Perspective taking in social phobic imagery. Behaviour Research and Therapy, 36, 631-634.

Wells, A., \& Papageorgiou, C. (1999). The observer perspective: Biased imagery in social phobia, agoraphobia, and blood/injury phobia. Behaviour Research and Therapy, 37, 653658. 
Table 1. Demographic characteristics of the study sample overall and in each group separately

\begin{tabular}{|c|c|c|c|c|}
\hline & $\begin{array}{c}\text { Overall } \\
\text { sample } \\
(n=68)\end{array}$ & $\begin{array}{l}\text { SAD group } \\
(n=38)\end{array}$ & $\begin{array}{l}\text { HC group } \\
(n=30)\end{array}$ & Test statistic ${ }^{\mathrm{a}}$ \\
\hline Gender $(\% \text { female })^{b}$ & 57.4 & 60.5 & 53.3 & $\chi^{2}=1.29, p=.700$ \\
\hline Ethnicity $^{\mathrm{c}}(\%)$ & & & & $\chi^{2}=3.93, p=.597$ \\
\hline White/European & 66.2 & 63.2 & 70 & \\
\hline Southeast Asian & 1.5 & 2.6 & 0 & \\
\hline Black & 1.5 & 0 & 3.3 & \\
\hline Other & 4.4 & 2.6 & 6.7 & \\
\hline Education $(\%)$ & & & & $\chi^{2}=0.38, p=.979$ \\
\hline Attended and/or graduated high-school & 7.4 & 7.9 & 6.7 & \\
\hline Full or part-time student & 39.7 & 44.7 & 33.3 & \\
\hline Employed full/part-time or self-employed & 48.5 & 39.5 & 60.0 & \\
\hline Unemployed & 7.4 & 10.5 & 3.3 & \\
\hline Temporarily unable to work & 2.9 & 5.3 & 0 & \\
\hline Retired & 1.5 & 0 & 3.3 & \\
\hline Marital status $(\%)$ & & & & $\chi^{2}=0.32, p=1.00$ \\
\hline Single & 64.7 & 65.8 & 63.3 & \\
\hline $\begin{array}{l}\text { Married/common law/engaged or } \\
\text { in committed relationship }\end{array}$ & 32.4 & 31.6 & 33.3 & \\
\hline Divorced/separated & 2.9 & 2.6 & 3.3 & \\
\hline \multicolumn{5}{|l|}{ Clinical characteristics } \\
\hline
\end{tabular}


SOCIAL PROBLEM SOLVING IN SOCIAL ANXIETY

Comorbid anxiety disorder $(\%)$

Comorbid mood disorder (\%)

Comorbid other $(\%)$

Number of comorbid diagnoses: M (SD)

SAD Clinical Severity Rating: M (SD)

SPIN: M (SD)

DASS-D: $M(\mathrm{SD})$

$\begin{array}{cccc} & 44.7 & - \\ - & 23.7 & - & \\ - & 26.3 & - & \\ - & 1.08(1.15) & - & \\ - & 4.97(.72) & - & t_{(55.93)}=-14.28, p<.001 \\ 25.00(19.00) & 39.29(12.28) & 6.90(5.94) & t_{(37.93)}=-7.10, p<.001 \\ 8.24(10.75) & 14.05(11.39) & 0.87(1.14) & \end{array}$

Note. SAD = Social Anxiety Disorder; HC = Healthy Control; SPIN = Social Phobia Inventory; DASS-D = Depression subscale of the Depression, Anxiety and Stress Scale - Short Version.

aValues presented for $\chi^{2}$ represent Fisher's Exact Test values.

bone participant in the clinical group identified as non-binary.

'Ethnic groups are based on Canadian census categories. 
SOCIAL PROBLEM SOLVING IN SOCIAL ANXIETY

Table 2. Performance on measures of social problem solving across the two groups

\begin{tabular}{lcc}
\hline & $\begin{array}{c}\text { SAD group } \\
(n=38)\end{array}$ & $\begin{array}{c}\text { HC group } \\
(n=30)\end{array}$ \\
\hline Megative problem orientation & $27.47(7.87)$ & M (SD) \\
Positive problem orientation & $10.66(4.35)$ & $6.50(4.95)$ \\
MEPS \# Relevant Steps & & $15.14(3.36)$ \\
Self & $5.74(2.95)$ & \\
Other & $5.92(2.06)$ & $6.57(2.67)$ \\
Overall & $11.66(4.47)$ & $5.67(2.50)$ \\
& & $12.23(4.70)$ \\
MEPS Effectiveness & & \\
Self & & \\
Other & $2.24(1.23)$ & $2.80(1.08)$ \\
Overall & $2.76(1.10)$ & $2.84(1.03)$ \\
MEPS Active & $5.00(1.94)$ & $5.64(1.93)$ \\
Self & & \\
Other & & \\
Overall & $7.71(2.36)$ & $7.88(1.57)$ \\
\hline No: SAD Social & $16.25(3.26)$ \\
\hline
\end{tabular}

Note: SAD = Social Anxiety Disorder; HC = Healthy Control; MEPS = Means-Ends Problem Solving task. Means are derived from repeated measures ANOVAs; as noted in footnote 3 within the manuscript, a problem solution was rated as having a relevance score of 0 , the effectiveness of the solution and the degree to which it was active were not rated. Thus, sample size differs for effectiveness and active variables: Effectiveness: $\mathrm{N}=34$ (SAD group), $\mathrm{N}=25$ (HC group); Active: $\mathrm{N}=34$ (SAD group), $\mathrm{N}=24$ (HC group). 
Table 3. Correlations between study variables

\begin{tabular}{|c|c|c|c|c|c|c|c|c|c|c|}
\hline & 1. & 2. & 3. & 4. & 5. & 6. & 7. & 8. & 9. & 10. \\
\hline 1. Relevant steps (self) & - & $.69^{* * *}$ & .14 & $.60^{* * *}$ & $.52^{* * *}$ & -.03 & -.08 & .03 & -.11 & -.12 \\
\hline 2. Effectiveness (self) & & - & $.38^{* *}$ & $.40^{* *}$ & $.49^{* * *}$ & .06 & -.21 & .12 & -.19 & -.17 \\
\hline 3. Active (self) & & & - & -.04 & .01 & .08 & $-.30^{*}$ & .09 & $-.34^{* *}$ & -.22 \\
\hline 4. Relevant steps (other) & & & & - & $.75^{* * *}$ & .12 & .03 & -.09 & .06 & -.01 \\
\hline 5. Effectiveness (other) & & & & & - & $.29^{*}$ & -.01 & -.13 & .02 & .15 \\
\hline 6. Active (other) & & & & & & - & .15 & -.19 & $.26^{*}$ & $.25^{*}$ \\
\hline 7. NPO & & & & & & & - & $-.64^{* * *}$ & $.88^{* * *}$ & $.57^{* * *}$ \\
\hline 8. PPO & & & & & & & & - & $-.58^{* * *}$ & $-.49^{* * *}$ \\
\hline 9. SPIN & & & & & & & & & - & $.65^{* * *}$ \\
\hline 10. DASS-D & & & & & & & & & & - \\
\hline
\end{tabular}

Note. NPO = Negative Problem Orientation; PPO = Positive Problem Orientation; SPIN = Social Phobia Inventory;

DASS-D $=$ Depression subscale of the Depression, Anxiety and Stress Scale - Short Version

${ }^{* * *} p<.001 ;{ }^{* *} p<.01 ;{ }^{*} p<.05$ 


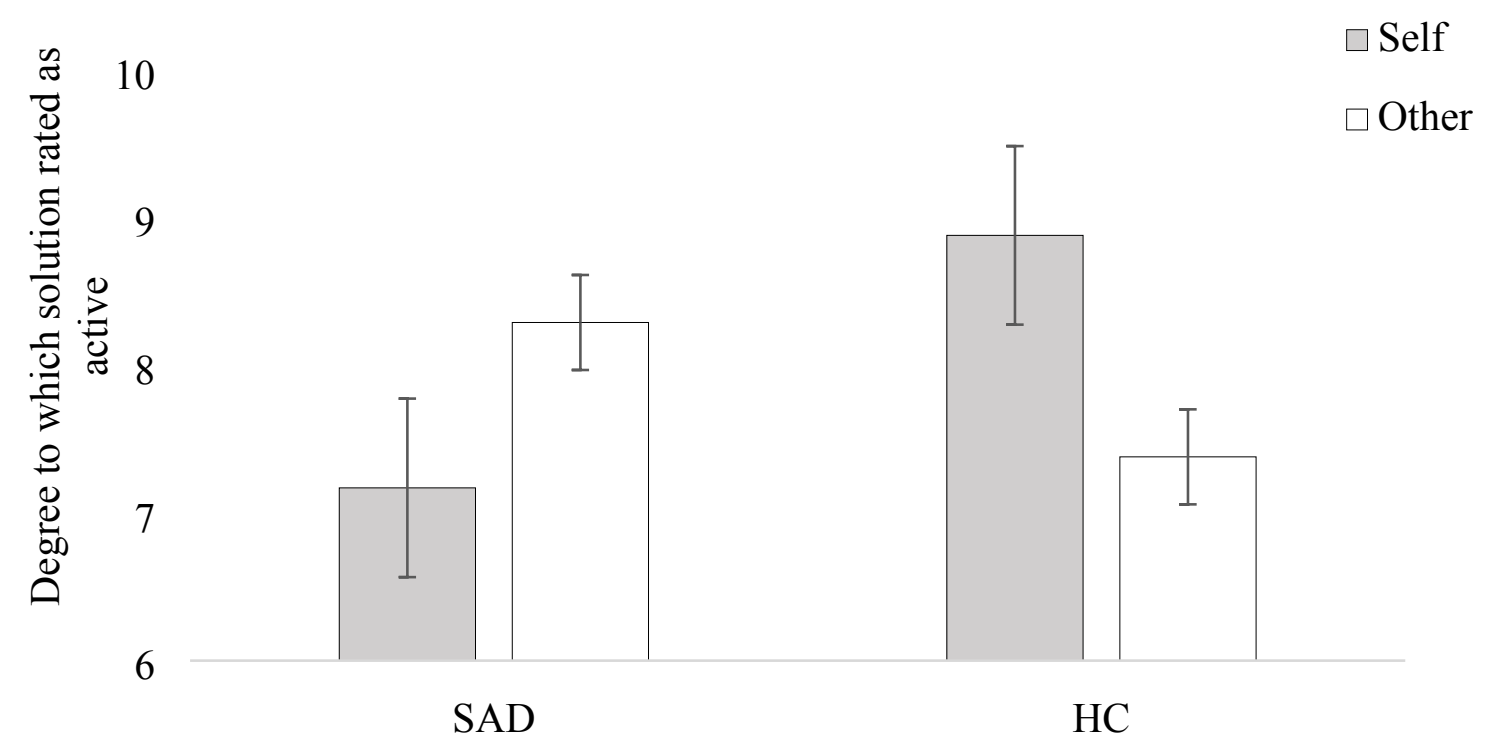

Figure 1. Graphical depiction of the significant interaction between perspective (self vs. other) and group (SAD vs. HC). SAD participants generated significantly less active solutions compared to HC participants when adopting a self-perspective. Within their respective group, $\mathrm{HC}$ participants generated significantly more active solutions when adopting a self vs. other perspective. 


\section{Appendix}

Examples of MEPS responses and associated effectiveness scores

Scenario: Resolving problem with friends (Set A: self)

1. If I notice that my friends are avoiding me, I would give it a bit of time before I become too worried. They could simply be in bad moods or there could be something else going on. If it lasts longer and seems fairly evident that it is directly targeted at me, I would simply have a conversation with him. I would be honest about how I have noticed them avoiding me and explain how that has made me feel. I would ask what was going on and if I had done something to hurt them. Hopefully they would forthcoming with the problem and I would do my very best to understand it. I would work with them to try and solve the problem. This could look like me needing to adjust my behaviours, us having to make a compromise, us needing to continue this conversation, or me deciding that their problem was not something that I could not change. Hopefully one of the former solutions would work and we would be able to civilly work out a solution. This would lead us back on the path to becoming close friends.

Effectiveness score $=2$

2. I directly ask my friends why they are avoiding me, while mentioning that there's no need to worry about hurting my feelings. With this information, I make changes to myself, behavior or the things we do together.

Effectiveness score $=1$

3. I text them, when they don't respond I get very anxious and I shut down and go into a depression. Binge watch netflix and cry. Sometimes for an afternoon, sometimes two days. When I snap out of it, I notice that they've finally gotten back to me and had just been busy.

Effectiveness score $=0$ 